\title{
AN RNA-SEQ-BASED APPROACH TO UNDERSTANDING THE IMMUNE SYSTEM OF THE AMERICAN LOBSTER (HOMARUS AMERICANUS)
}

\author{
Clark, K. Fraser'1, Spencer J. Greenwood ${ }^{1}$ \\ ${ }^{1}$ Department of Biomedical Sciences and AVC Lobster Science Centre, Atlantic Veterinary College, University of \\ Prince Edward Island, Charlottetown PE, Canada \\ The growth and accessibility of next-generation sequencing technologies has significantly enhanced our \\ ability to determine the molecular mechanisms responsible for complex physiological processes in non- \\ model organisms like crustaceans. The power and limitations of this technology are in the huge amount of \\ data that is generated and the bioinformatic annotation of this data. Proper annotation is fundamental for \\ understanding the molecular basis of a phenotype or condition. The American lobster (Homarus \\ americanus) fishery is essential to the economic well-being of hundreds of small coastal Canadian and \\ American communities. The long-term health and sustainability of this fishery is an important area of \\ study. In addition, it is an excellent model for comparative physiological studies with other crab and \\ shrimp species which are the basis of global aquaculture production. Understanding of decapod immune \\ systems is critical as the most significant factor impacting sustainability and expansion of global shrimp \\ aquaculture is disease. This study will use RNA-Seq studies of the American lobster to demonstrate an \\ approach that significantly enhances immune-related annotation of genes involved in the crustacean \\ immune response. In addition, it will highlight the similarities and differences between the lobster \\ humoral immune response to Gram-positive bacterial (Aerococcus viridans var. homari) and \\ scuticociliate (Anophryoides haemophila) challenges.
}

\section{KEYWORDS}

Transcriptome, American lobster, Crustacean Immunology, RNA-Seq, Gene Annotation

Corresponding author. Tel.: 902-5666028

E-mail address:fclark@upei.ca 